\title{
Analysis of Aminotransferases in Predialysis Chronic Kidney Disease Patients
}

\author{
Mujeeb Olushola Shittu ${ }^{1}$, Ayodele Adelakun ${ }^{1}$, Anifat Eegunjobi ${ }^{1}$, \\ Olufemi Idowu ${ }^{1}$, Bashirat Tolulope Shittu ${ }^{2}$ \\ ${ }^{I}$ (Department of Chemical Pathology, Ladoke Akintola University of Technology Teaching Hospital, Ogbomoso, \\ Nigeria) \\ ${ }^{2}$ (Department of Haematology, Ladoke Akintola University of Technology Teaching Hospital, Osogbo, Nigeria)
}

\begin{abstract}
The incidence of chronic kidney disease (CKD) is on the increase in Africa than in developed world. Alanine and aspartate aminotransferases are used to determine the integrity of the liver. This study on the analysis of aminotransferases was carried out on CKD patients who have not undergone dialysis therapy. The objective of this study was to determine the levels of alanine and aspartate aminotransferases in patients with CKD and compared to healthy individuals. A total of 100 subjects (both male and female adults) were used to carry out the study. 50 were CKD patients who have not undergone dialysis therapy, while the remaining 50 were apparently healthy adults. The levels of aspartate aminotransferase (AST) and alanine aminotransferase (ALT) were estimated using colorimetric method. The results indicated that both AST and ALT were significantly low $(p<0.05)$ in both sexes when compared with their counterparts in the control group. In conclusion, the decrease in levels of aminotransferases in CKD patients who have not undergone dialysis therapy has observed in this study suggests that renal impairment has an impact on the liver enzymes. Further studies are however needed to establish the cause of hypoaminotransferasemia in patients with CKD.
\end{abstract}

Keywords: Aminotransferases, chronic kidney disease, predialysis

\section{Introduction}

Chronic renal failure is a worldwide public health problem with more prevalence in Africa than in developed countries [1]. A recent study confirmed that there is no difference in prevalence of chronic kidney disease (CKD) between urban and rural areas [2].

In Nigeria, CKD mainly affects young adults with hypertensive nephrosclerosis, diabetes mellitus and infection-related chronic glomerulonephritis as the commonest causes [3]. Morbidity and mortality are high because most of the affected cannot either access or afford renal replacement therapy [4].

Patients with CKD who have undergone hemodialysis have been shown to present with lower aminotransferase activity than predialysis patients [5]. Hemodilution have been reported to alter the serum levels of liver enzymes $[6,7]$.

The most common cause of liver disease in hemodialysis patients is HCV [8]. CKD patients with HCV infection undergoing chronic hemodialysis have been shown to present with lower level of alanine aminotransferase concentration than HCV infected patients with normal renal function [9].

The low levels of liver aminotransferases in hemodialysis patients was reported to be in part due to the deficiency of Pyridoxal-5-phosphate (PLP) which is a coenzyme for these aminotransferases [10].

There are scientific publications in different parts of the world on the serum level of aminotransferases in CKD patients undergoing hemodialysis $[5,10,11]$. However, there is little information on the comparison of aminotransferases level in predialysis CRF patients with healthy individual, especially in Nigeria. Therefore, this present work was carried out in order to determine the levels of aminotransferases in Nigerian patients affected with CKD.

\section{Patients And Methods}

This present study was conducted in Ladoke Akintola University of Technology Teaching Hospital, Ogbomoso, Southwest Nigeria. The study group comprised of 100 adult subjects. Fifty of them (30 males and 20 females) who were apparently healthy adults were used as control while the remaining 50 (30 males and females) were patients presenting with CKD and who have not undergone dialysis.

To be included in the present study, patients had to be at least 20 years old, have CKD, and have not undergone dialysis therapy. All patients with estimated glomerular filtration rate (eGFR) $\leq 60 \mathrm{ml} / \mathrm{min} / 1.73 \mathrm{~m}^{2}$ for $\geq 3$ months had CKD with reference to kidney disease improving global outcome (KDIGO) evaluation system. Exclusion criteria for both groups were: patients who had previously been diagnosed with Hepatitis B infection, other liver diseases or if they consumed $\geq 40 \mathrm{~g} /$ day of alcohol. The subjects were 
grouped into 4 as thus; Group 1- healthy males, Group 2- healthy females, Group 3- male patients with CRF, Group 4- female patients with CRF.

Sample Collection was carried out under aseptic precaution; $5 \mathrm{ml}$ of whole blood was collected into heparin bottle. Plasma was separated from the whole blood cells after centrifugation. The plasma AST and ALT were determined using colorimetric method with Randox Diagnostic test kit. Also, creatinine and urea were determined using kinetic and end-point methods respectively with Randox Diagnostic test kit.

The statistical analysis was carried out using Statistical Package for Social Sciences (SPSS) version 17.0 for Windows. Student's t-test was used to evaluate the mean differences between the predialysis CKD patients and healthy controls. The degree of correlation between measurements was assessed using the Pearson's correlation coefficient test. P-values $<0.05$ were considered to be statistically significant.

\section{Results}

Table 1 shows comparison of parameters between predialysis CKD patients and controls. There was no significant difference between the ages of the predialysis CKD patients $(45.3 \pm 13.2)$ and the control group (47.0 \pm 11.4$)$. The mean values of plasma creatinine and urea in CKD patients were $(663.0 \pm 252.0$ and 23.1 \pm 11.1$)$ respectively when compared to controls $(85.4 \pm 13.4$ and $5.7 \pm 1.2)$ indicating the renal impairment in them. The AST and ALT were significantly low in predialysis CKD patients $(\mathrm{P}<0.001)$ compared with controls. There was significantly urea and creatinine in CKD patients when compared with the controls.

AST and ALT were both significantly low in male subjects when compared with the controls. Table 2. Similarly, TABLE 3 shows the results of AST and ALT in female predialysis CKD patients compared with female controls. There was a significantly low AST and ALT levels in the female subjects when compared with the controls.

Table 1. Showing Comparison Of Parameters Between CKD Patients And Healthy Individuals

\begin{tabular}{|l|l|l|c|}
\hline & $\begin{array}{l}\text { CKD Patients } \\
\text { n=50 } \\
\text { mean } \pm \text { SD }\end{array}$ & $\begin{array}{l}\text { Control } \\
\text { n=50 } \\
\text { mean } \pm \text { SD }\end{array}$ & P-value \\
\hline Age (yr) & $45.3 \pm 13.2$ & $47.0 \pm 11.4$ & 0.06 \\
Urea (mmol/l) & $23.1 \pm 11.1$ & $5.7 \pm 1.2$ & $<0.001^{*}$ \\
Creatinine (mmol/l) & $663.0 \pm 252.0$ & $85.4 \pm 13.4$ & $<0.001^{*}$ \\
ALT (IU/L) & $7.1 \pm 6.6$ & $17.1 \pm 5.0$ & $<0.001^{*}$ \\
AST (IU/L) & $17.1 \pm 7.1$ & $23.8 \pm 3.2$ & $<0.001^{*}$ \\
\hline
\end{tabular}

*P-value is significant $(<0.05)$

Table 2. The means \pm SD AST and ALT of Male CKD Patients As Compared With Male Controls

\begin{tabular}{|l|l|l|}
\hline Groups & AST (IU/L) & ALT (IU/L) \\
\hline Group 1 & $22.9 \pm 3.2$ & $17.1 \pm 4.7$ \\
Group 3 & $17.0 \pm 5.9$ & $6.6 \pm 3.8$ \\
P-value & $0.001^{*}$ & $<0.001^{*}$ \\
\hline
\end{tabular}

*P-value is significant $(<0.05)$

Table 3. The means \pm SD AST and ALT of Female CKD Patients As Compared With Female Controls

\begin{tabular}{|l|l|l|}
\hline Groups & AST (IU/L) & ALT (IU/L) \\
\hline Group 2 & $25.0 \pm 2.8$ & $17.1 \pm 5.6$ \\
Group 4 & $17.3 \pm 8.6$ & $7.8 \pm 9.3$ \\
P-value & $0.003^{*}$ & $0.008^{*}$ \\
\hline
\end{tabular}

*P-value is significant $(<0.05)$

\section{Discussion}

When serum transaminases were evaluated in HBV and HCV infection in HD patients and controls, the AST was reported to be non-significant while ALT was significantly depressed. Serum transaminases are also reported to be decreased in HD patients and the cut-off value of serum transaminases should be set at lower levels [12].

ALT levels were significantly lower in patients with ESRD and had less severe hepatitis [13]. HCVrelated liver disease becomes begnin in patients on regular dialysis treatment due to the release of hepatocyte growth factor caused by dialysis [14]. Another study which compared patients on continuous ambulatory peritoneal dialysis (CAPD) and healthy adults found a mean ALT concentration of $15 \mathrm{IU} / \mathrm{L}$ in the CAPD patients as opposed to $22 \mathrm{IU} / \mathrm{L}$ in the control group $(\mathrm{p}<0.0001)$ [15]. Such data support the fact that regardless of HD, patients with CRF have lower levels of ALT.

Researchers have suggested that, the hypothesis to explain the lower levels of ALT in patients with CRF could be the severity of the impairment of renal function caused by glomerular dysfunction. Previous researches have revealed that ALT serum levels are lower in patients with CKD compared with patients with 
normal renal function. Hemodilution and deficiency of Pyridoxal-5-phosphate have been reported to be responsible [6, 10]. Hypotension-induced liver cell injury during HD session could explain the lower serum levels of ALT in patients with CKD.

In the present study, the plasma ALT and AST levels in CKD patients who have not undergone hemodialysis also decreased significantly when compared with normal individuals. This decrease may be a consequence of the impaired renal function and not Hemodilution as a result of hemodialysis or liver diseases. This report is similar to that reported by Fabrizi et al. [5] who compared CKD patients on HD with CKD patients on conservative treatment (predialysis) and reported that the ALT serum levels were reduced concomitantly with the progression of renal dysfunction.

\section{Conclusion}

The present study has revealed that aminotransferase levels in patients with CKD who have not undergone HD therapy are significantly lower compared with healthy adults irrespective of the sex. The decrease in aminotransferase levels may be due to the severity of renal impairment since the patients have not undergone HD treatment, other factors may also be responsible. Therefore, further studies are however needed to establish the causes of hypoaminotransferasemia in patients with CKD.

\section{References}

[1]. Naicker S. End-stage renal disease in sub-Saharan Africa. Ethn Dis 2009;19:S13-5.

[2]. John W S, Bocheng J, Scott T, Nicole H, Romita M, Saraladevi N, Uptal. The epidemiology of chronic kidney disease in subSaharan. Africa: A systematic review and meta-analysis. The Lancet Global Health 2014;2:174-81.

[3]. Alebiosu CO, Ayodele OO, Abbas A, Olutoyin IA. Chronic renal failure at the olabisi onabanjo university teaching hospital, sagamu, Nigeria. African Health Sciences 2006;6:132-8

[4]. Arogundade FA, Barsoum RS. CKD prevention in Sub-Saharan Africa: A call for governmental, nongovernmental, and communitysupport. Am J Kidney Dis 2008;51:515-23.

[5]. Fabrizi F, Lunghi G, Finazzi S, Colucci P, Pagano A, Ponticelli C, Locatelli F. Decreased serum aminotransferase activity in patients with chronic renal failure: Impact on the detection of viral hepatitis. Am J Kidney Dis 2001, 38(5):1009-15.

[6]. Isabella RO, Edmundo PA, Maria AG, Tiago CP, Izolda FM, Luiz LJ. Liver enzymes in patients with chronic kidney disease undergoing peritoneal dialysis and hemodialysis. Clinics (Sao Paulo) 2012;67:131-4.

[7]. Edmundo PL, Luis HBC, Jorge BC, Carlos FL, Amaro M, Andrade MM, Paulo CA, Roberto M, Rui LC, Sergio CC. Serum alanine aminotransferase levels, hematocrit rate and body weight corrections before and after hemodialysis session. Clinics (Sao Paulo) 2009;64:941-5.

[8]. Gane E, Pilmore H. Management of chronic viral hepatitis before and after renal transplantation. Transplantation 2002;74:427-37.

[9]. Al-Wakeel J, Malik GH, al-Mohaya S, Mitwalli A, Baroudi F, el Gamal H, Kechrid M. Liver disease in dialysis patients with antibodies to hepatitis C virus. Nephrol Dial Transplant 1996;11:2265-8.

[10]. Ono K, Ono T, Matsumata T. The pathogenesis of decreased aspartate aminotransferase and alanine aminotransferase activity in the plasma of hemodialysis patients: The role of vitamin B6 deficiency. Clin Nephrol 1995;43:405-8.

[11]. Yasuda K, Okuda K, Endo N, Ishiwatari Y, Ikeda R, Hayashi H, Yokozeki K, Kobayashi S, Irie Y. Hypoaminotransferasemia in patients undergoing long-term hemodialysis: Clinical and biochemical appraisal. Gastroenterology 1995;109:1295-300.

[12]. Guh JY, Lai YH, Yang CY, Chen SC, Chuang WL, Hsu TC, Chen HC, Chang WY, Tsai JH. Impact of decreased serum transaminase levels on the evaluation of viral hepatitis in hemodialysis patients. Nephron 1995;69:459-65.

[13]. Cotler SJ, Diaz G, Gundlapalli S, Jakate S, Chawla A, Mital D, Jensik S, Jensen DM. Characteristics of hepatitis C in renal transplant candidates. J Clin Gastroenterol 2002;35:191-5.

[14]. Rampino T, Arbustini E, Gregorini M, Guallini P, Libetta C, Maggio M, Ranghino A, Silini E, Soccio G, Dal Canton A. Hemodialysis prevents liver disease caused by hepatitis C virus: Role of hepatocyte growth factor. Kidney Int 1999;56:2286-91.

[15]. Hung KY, Lee KC, Yen CJ, Wu KD, Tsai TJ, Chen WY: Revised cutoff values of serum aminotransferase in detecting vir hepatitis among CAPD patients: Experience from Taiwan, an endemic area for hepatitis B. Nephrol Dial Transplant 1997;12:180-3. 